Military Technical College, Kobry El-Kobbah, Cairo, Egypt $9^{\text {th }}$ International Conference On Aerospace Sciences \& Aviation Technology

\title{
MODAL CHARACTERISTICS OF HALF CYLINDRICAL SHELL ASSEMBLED WITH TWO PLATES USING RECEPTANCE TECHNIQUE
}

\author{
El-Maddah" M. M., Sherif* H. A., Badawy A.
}

\begin{abstract}
Many shell type structures are combinations of basic shell elements. Several methods of evaluating the vibration characteristics of such combinations have been developed. The receptance method is considered as one of the most important methods. This paper introduces the calculation of natural frequencies and mode shapes of half-cylindrical shell structure assembled with two uniform plates at its straight edges, based on the receptance method. The receptance method inputs are the response of each element in the system, shell and plates. This will reduce the effort done in response calculation of complex system to the response calculation of simple structural elements.
\end{abstract}

\section{Key Words}

Receptance, shell, plate, substructure.

\footnotetext{
* Egyptian Armed Forces
} 


\section{Nomenclature}

$\begin{array}{ll}a & \text { Plate length } \\ b & \text { Plate width } \\ E & \text { Modulus of elasticity } \\ F & \text { Force } \\ h & \text { Thickness } \\ M & \text { Bending moment } \\ n, p, m & \text { indices } \\ R & \text { Shell radius } \\ \alpha, \beta, \gamma & \text { Receptance functions } \\ \eta & \text { Steady state response } \\ \theta & \text { Angular coordinate } \\ \omega & \text { Natural frequency } \\ \Delta & \text { Receptance function } \\ \delta & \text { Delta Dirac function } \\ v & \text { Poisson s ratio } \\ \rho & \text { Mass density }\end{array}$

\section{Introduction}

The receptance function is defined as the ratio between the Fourier transformation of the displacement and the applied load. The receptance method is used by W. Soedel to calculate the response of some simple structures that consist of plate with either concentrated mass or spring [1]. S. Azimi [2,3] calculated the response of a duct that consists of eight plates. Experimental investigation of the response using substructure technique is introduced by M. El-Maddah [4]. At the present state of the art, useful line receptance cannot be formulated for all structural line connections. The prerequisite is that the two substructures, that are to be connected along a line, have individual natural mode shapes that coincide along the lines of connection. In such cases, the spatial variable can be eliminated therefore the line receptance reduces into the equivalent of a point receptance and the receptance becomes a function of frequency only. This paper introduces natural frequencies and mode shapes calculation of half-cylindrical shell structure assembled with two uniform plates at its straight edges, based on the receptance method

\section{Theoretical Background}

The receptance method is employed to calculate the vibration characteristics of three substructures $B, C$ and $D$. The substructures are connected at two locations as shown in Fig. 1.

The equilibrium of forces and the continuity of displacements for the given configuration are:

$$
\begin{array}{ll}
\mathrm{f}_{\mathrm{B} 1}+\mathrm{f}_{\mathrm{Cl}}=0 & , \mathrm{x}_{\mathrm{B} 1}=\mathrm{x}_{\mathrm{Cl}} \\
\mathrm{f}_{\mathrm{C} 2}+\mathrm{f}_{\mathrm{D} 2}=0 & , \mathrm{x}_{\mathrm{C} 2}=\mathrm{x}_{\mathrm{D} 2}
\end{array}
$$


Where all forces and all displacements are expressed as harmonic functions. In terms of receptance:

$$
\begin{aligned}
& \mathrm{x}_{\mathrm{B} 1}=\beta_{11} \mathrm{f}_{\mathrm{B} 1} \\
& \mathrm{x}_{\mathrm{C1}}=\gamma_{11} \mathrm{f}_{\mathrm{Cl}}+\gamma_{12} \mathrm{f}_{\mathrm{C} 2} \\
& \mathrm{x}_{\mathrm{C} 2}=\gamma_{21} \mathrm{f}_{\mathrm{Cl}}+\gamma_{22} \mathrm{f}_{\mathrm{C} 2} \\
& \mathrm{x}_{\mathrm{D} 2}=\psi_{22} \mathrm{f}_{\mathrm{D} 2}
\end{aligned}
$$

where $f_{B 1}, f_{C 1}, f_{C 2}, f_{D 1}$ and $x_{B 1}, x_{C 1}, x_{C 2}, x_{D 1}$ are the magnitudes of the harmonic forces and harmonic displacements, respectively.

By substitution of eq. (1) in eq. (2)

$$
\begin{aligned}
& \beta_{11} \mathrm{f}_{\mathrm{B} 1}=\gamma_{11} \mathrm{f}_{\mathrm{Cl}}+\gamma_{12} \mathrm{f}_{\mathrm{C} 2} \\
& \gamma_{12} \mathrm{f}_{\mathrm{Cl}}+\gamma_{22} \mathrm{f}_{\mathrm{C} 2}=\psi_{22} \mathrm{f}_{\mathrm{D} 2}
\end{aligned} \longrightarrow \begin{aligned}
& \mathrm{f}_{\mathrm{B} 1}\left(\beta_{11}+\gamma_{11}\right)-\gamma_{12} \mathrm{f}_{\mathrm{C} 2}=0 \\
& \mathrm{f}_{\mathrm{C} 2}\left(\psi_{22}+\gamma_{22}\right)-\gamma_{12} \mathrm{f}_{\mathrm{B} 1}=0
\end{aligned}
$$

Writing equations (3) and (4) in matrix form

$$
\left[\begin{array}{cc}
\beta_{11}+\gamma_{11} & -\gamma_{12} \\
-\gamma_{12} & \psi_{22}+\gamma_{22}
\end{array}\right]\left\{\begin{array}{l}
F_{B 1} \\
F_{\mathrm{C} 2}
\end{array}\right\}=\left\{\begin{array}{l}
0 \\
0
\end{array}\right\}
$$

For the non-trivial solution of the problem, the determinant of the matrix should vanish: namely;

$$
\Delta=\left|\begin{array}{cc}
\beta_{11}+\gamma_{11} & -\gamma_{12} \\
-\gamma_{12} & \psi_{22}+\gamma_{22}
\end{array}\right|=0
$$

This is the frequency equation for the system.

\section{Substructure Coupling by receptance method}

The proposed structure can be divided into its elements as shown in Fig. 2. In the following the derivation of receptance of plate and shell basic elements is given. The total receptance is then obtained leading to evaluation of the modal characteristics of the proposed structure.

\section{Plate receptance}

The problem of calculating the receptance for a rectangular plate that is simply supported at all edges with bending moment applied at edge $\mathrm{z}=\mathrm{a}$ is considered here. The bending moment and the slope response have to be both distributed sinusoidally in the x-direction, see Fig. 2 . The receptance of such plate is the ratio of harmonic slope response to harmonic moment excitation. The line moment is expressed as a distributed moment by using a Dirac delta function in z-direction which defines the occurrence of the moment at $z=a$.

From this definitions, it is possible to define the following integration rule:

$$
\int_{0}^{\mathrm{a}} \mathrm{M}(\mathrm{z}) \delta(\mathrm{z}-\mathrm{a}) \mathrm{dz}=\mathrm{M}(\mathrm{a})
$$

The general solution for the transverse displacement is expressed as[1] 


$$
v(x, z, t)=\sum_{p=1}^{\infty} \eta_{p}(t) v_{p}(x, z)
$$

where $\eta_{p}(t)$ is the modal participation factor and $V(x, z)$ is again the mode shape of the plate, neglecting the stiffness effects. The modal participation factor, $\eta_{p}(t)$, is calculated for the steady state harmonic response.

$$
\ddot{\eta}_{\mathrm{p}}+\omega_{\mathrm{p}}^{2} \eta_{\mathrm{p}}=\mathrm{F}_{\mathrm{p}} \mathrm{e}^{\mathrm{i \omega t}}
$$

The steady state response is:

$$
\eta_{p}(t)=\frac{F_{p}^{*}}{\left(\omega_{p}^{2}-\omega^{2}\right)^{2}} \exp [i(\omega t-\phi)], i=\sqrt{-1}
$$

where

$$
\begin{aligned}
& F_{p}^{*}=\frac{1}{\rho h N_{p}} \int_{0}^{b} \int_{0}^{a} V_{p}(x, z) \frac{\partial M(x, z)}{\partial z} d z d x \\
& N_{p}=\int_{0}^{b} \int_{0}^{a} V_{p}^{2}(x, z) d z d x
\end{aligned}
$$

and

$$
M=M(x, z) e^{i \omega t}=M_{0} \sin \left(p \pi \frac{x}{b}\right) \delta(z-a) e^{i \omega t}
$$

$M(x, z)$ is the applied moment per unit area in the $x$-direction in units $\left[\mathrm{Nm} / \mathrm{m}^{2}\right] ; p$ is an integer, $M_{0}$ is moment per unit length in units $[\mathrm{Nm} / \mathrm{m}]$.

When all edges are simply supported

where

$$
\mathrm{V}_{\mathrm{p}}(\mathrm{x}, \mathrm{z})=\mathrm{V}_{\mathrm{mn}}(\mathrm{x}, \mathrm{z})=\mathrm{A} \sin \left(\mathrm{m} \pi \frac{\mathrm{x}}{\mathrm{b}}\right) \sin \left(\mathrm{n} \pi \frac{\mathrm{z}}{\mathrm{a}}\right)
$$

$$
\begin{aligned}
& \omega_{m n}=\pi^{2}\left((m / b)^{2}+(n / a)^{2}\right) \sqrt{D / \rho h} \text { And } D=\frac{E h^{3}}{12\left(1-v^{2}\right)} \\
& N_{k}=\int_{0}^{b} \int_{0}^{a} \sin \left(\frac{n \pi z}{a}\right) \sin \left(\frac{m \pi x}{b}\right) d x d z=\frac{a b}{4} \\
& F_{p}^{*}=\frac{4 M_{0}}{a b h \rho}\left[\int_{0}^{a} \sin \left(\frac{n \pi z}{a}\right) \frac{\partial}{\partial z}(\delta(z-a)) d z\right]\left[\int_{0}^{b} \sin \left(\frac{m \pi x}{b}\right) \sin \left(\frac{p \pi x}{b}\right) d x\right]
\end{aligned}
$$

Leading to:

$$
\mathrm{F}_{\mathrm{p}}^{*}=(-1)^{\mathrm{n}+1} \frac{2 \mathrm{M}_{\mathrm{o}} \mathrm{n} \pi}{\mathrm{a}^{2} \mathrm{~h} \rho}
$$

The steady state response is then

$$
V(x, z)=\frac{2 M_{o} \pi}{a^{2} h \rho} \sum_{n=1}^{\infty} \frac{(-1)^{n+1} n}{\left(\omega_{p}^{2}-\omega^{2}\right)^{2}} \sin \left(\frac{n \pi z}{a}\right) \sin \left(\frac{p \pi x}{b}\right)
$$

The receptance of interest here is defined as:

$\alpha_{11}=\frac{d V(x, z) / d z}{M_{0} \sin (p \pi x / b)} \alpha_{11}(x, z)=\frac{2 \pi^{2}}{a^{3} h \rho} \sum_{n=1}^{\infty} \frac{(-1)^{n+1} n^{2}}{\left(\omega_{p}^{2}-\omega^{2}\right)^{2}} \cos \left(\frac{n \pi z}{a}\right)$

At $z=a$, connection location 


$$
\alpha_{11}(\mathrm{x}, \mathrm{a})=-\frac{2 \pi^{2}}{\mathrm{a}^{3} \mathrm{~h} \rho} \sum_{\mathrm{n}=1}^{\infty} \frac{\mathrm{n}^{2}}{\left(\omega_{\mathrm{p}}^{2}-\omega^{2}\right)^{2}}
$$

\section{Shell receptance}

The same method is used to calculate the receptance of a half-circular cylindrical shell. Considering all edges to be simply supported.

$$
\begin{aligned}
\mathrm{W}_{\mathrm{p}} & =\mathrm{W}_{\mathrm{mn}}(\mathrm{x}, \theta)=\mathrm{A} \sin \left(\frac{\mathrm{m} \pi \mathrm{x}}{\mathrm{b}}\right) \sin \left(\frac{\mathrm{n} \pi \theta}{\alpha}\right) \\
\mathrm{N}_{\mathrm{p}} & =\mathrm{R} \int_{00}^{\pi \mathrm{b}} \int_{\mathrm{p}} \mathrm{W}_{\mathrm{p}}^{2}(\mathrm{x}, \theta) \mathrm{dxd} \theta \\
& =\mathrm{R} \mathrm{b} \pi / 4 \\
\mathrm{~F}_{\mathrm{p}}^{*} & =\frac{1}{\rho \mathrm{phN}_{\mathrm{p}}} \int_{0}^{\pi \mathrm{b}} \int_{0}^{\mathrm{b}} \mathrm{W}_{\mathrm{p}}(\mathrm{y}, \theta) \frac{\partial \mathrm{M}(\mathrm{y}, \theta)}{\partial \theta} \mathrm{dyd} \theta
\end{aligned}
$$

The resultant $M(y, \theta)$ can be expressed as

$$
\mathrm{M}(\mathrm{y}, \theta)=\mathrm{M}_{1}(\mathrm{y}, \theta)-\mathrm{M}_{2}(\mathrm{y}, \theta)
$$

where

$$
\begin{aligned}
& \mathrm{M}_{1}(\mathrm{y}, \theta)=\mathrm{M}_{\mathrm{ol}} \sin \left(\mathrm{p} \pi \frac{\mathrm{y}}{\mathrm{b}}\right) \delta(\theta) \\
& \mathrm{M}_{2}(\mathrm{y}, \theta)=\mathrm{M}_{\mathrm{o} 2} \sin \left(\mathrm{p} \pi \frac{\mathrm{y}}{\mathrm{b}}\right) \delta(\theta-\pi)
\end{aligned}
$$

$\mathrm{F}_{\mathrm{p}}^{*}$ is found to be

$$
\begin{aligned}
& \mathrm{F}_{\mathrm{p}}^{*}=\left.\mathrm{F}_{\mathrm{p}}^{*}\right|_{\mathrm{M}_{1}}-\left.\mathrm{F}_{\mathrm{p}}^{*}\right|_{\mathrm{M}_{2}} \\
& \left.\mathrm{~F}_{\mathrm{p}}^{*}\right|_{\mathrm{M}_{1}}=-\frac{2 \mathrm{M}_{\mathrm{ol}} \mathrm{m}}{\mathrm{hR} \pi \rho}
\end{aligned}
$$

and

$$
\left.\mathrm{F}_{\mathrm{p}}^{*}\right|_{\mathrm{M}_{2}}=-\frac{2 \mathrm{M}_{\mathrm{o} 2} \mathrm{~m}}{\mathrm{hR} \pi \rho} \cos (\mathrm{m} \pi)
$$

The steady state solution is then

$$
\begin{aligned}
& \mathrm{W}(\theta, \mathrm{y})=\left.\mathrm{W}(\theta, \mathrm{y})\right|_{\mathrm{M}_{1}}-\left.\mathrm{W}(\theta, \mathrm{y})\right|_{\mathrm{M}_{2}} \\
& \left.\mathrm{~W}(\theta, \mathrm{y})\right|_{\mathrm{M}_{1}}=-\frac{2 \mathrm{M}_{\mathrm{ol}}}{\mathrm{R} \pi \mathrm{h} \rho} \sum_{\mathrm{m}=1}^{\infty} \frac{\mathrm{m}}{\gamma_{\mathrm{p}}} \sin \left(\frac{\mathrm{p} \pi \mathrm{y}}{\mathrm{b}}\right) \sin (\mathrm{m} \theta) \\
& \left.\mathrm{W}(\theta, \mathrm{y})\right|_{\mathrm{M}_{2}}=-\frac{2 \mathrm{M}_{\mathrm{o} 2}}{\mathrm{R} \pi \mathrm{h} \rho} \sum_{\mathrm{m}=1}^{\infty} \frac{\mathrm{m} \cos (\mathrm{m} \pi)}{\gamma_{\mathrm{p}}} \sin \left(\frac{\mathrm{p} \pi \mathrm{y}}{\mathrm{b}}\right) \sin (\mathrm{m} \theta)
\end{aligned}
$$

where the natural frequency of shell structure of the simply supported curved panel with opening angle $\alpha=\pi$ 


$$
\omega_{m p}=\frac{1}{R} \sqrt{\frac{(p \pi R / b)^{4}}{\left.(p \pi R / b)^{2}+m^{2}\right]^{2}}+\frac{(h / R)^{2}}{12\left(1-v^{2}\right)^{2}}\left[(p \pi R / b)^{2}+m^{2}\right]^{2}} \sqrt{\frac{E}{\rho}}
$$

and

$$
\gamma_{\mathrm{p}}=\sqrt{\omega_{\mathrm{p}}^{2}+\frac{\mathrm{K}}{\rho \mathrm{\rho h}}-\frac{\mathrm{c}^{2}}{4 \rho^{2} \mathrm{~h}^{2}}}
$$

The receptance of interest here is defined as:

$$
\alpha_{i j}(\theta, y)=\frac{\left.d W(\theta, y)\right|_{M_{j}} / d \theta}{(-1)^{j-1} M_{\mathrm{oj}} \sin (\mathrm{p} \pi \mathrm{y} / \mathrm{b})} \quad \text { at } \theta=\theta_{\mathrm{i}}, \mathrm{i}, \mathrm{j}=1,2, \theta_{1}=0, \theta_{2}=\pi
$$

e.g.

$$
\begin{aligned}
& \alpha_{11}(0, y)=\frac{\left.d W(\theta, y)\right|_{M_{1}} / d \theta}{M_{01} \sin (\mathrm{p} \pi \mathrm{y} / \mathrm{b})}=-\frac{2}{\rho \mathrm{hR} \pi} \sum_{\mathrm{m}=1}^{\infty} \frac{\mathrm{m}^{2}}{\left(\omega_{\mathrm{p}}^{2}-\omega^{2}\right)^{2}} \\
& \alpha_{22}(\pi, \mathrm{y})=\frac{\left.\mathrm{dW}(\mathrm{x}, \mathrm{y})\right|_{\mathrm{M}_{2}} / \mathrm{d} \theta}{\mathrm{M}_{\mathrm{o} 2} \sin (\mathrm{p} \pi \mathrm{y} / \mathrm{b})}=-\frac{2}{\rho \mathrm{hR} \pi} \sum_{\mathrm{m}=1}^{\infty} \frac{\mathrm{m}^{2}}{\left(\omega_{\mathrm{p}}^{2}-\omega^{2}\right)^{2}} \\
& \alpha_{12}(\theta, \mathrm{y})=\alpha_{21}(\theta, \mathrm{y})=\frac{\left.\mathrm{dW}(\mathrm{x}, \mathrm{y})\right|_{\mathrm{M}_{2}} / \mathrm{d} \theta}{\mathrm{M}_{\mathrm{o} 2} \sin (\mathrm{p} \pi \mathrm{y} / \mathrm{b})} \\
& \alpha_{12}(0, \mathrm{y})=-\frac{2}{\rho \mathrm{hR} \pi} \sum_{\mathrm{m}=1}^{\infty} \frac{\mathrm{m}^{2} \cos (\mathrm{m} \pi)}{\left(\omega_{\mathrm{p}}^{2}-\omega^{2}\right)^{2}}
\end{aligned}
$$

$\alpha_{11}$ and $\alpha_{22}$ are the same because of symmetry while $\alpha_{12}$ and $\alpha_{21}$ are the same because of Maxwell s reciprocity property.

\section{Discussion of Resuits}

Substituting equations (19), (32), (34) in equation (6) gives the natural frequencies of the assembled structure. For plate dimension $4 \times 4$ with thickness of $10 \mathrm{~mm}$, shell dimensions $\phi 4 \times 4$ with thickness of $10 \mathrm{~mm}$ both of material with modulus of elasticity $207 \mathrm{GPa}$, density $7860 \mathrm{~kg} / \mathrm{m}^{3}$ 0.3 .

The number of half waves in the longitudinal direction, $x$-direction, is defined by $p$. The cross sectional mode view is defined by $m$. The graphical solution of equation (6) is given in Fig. 3 for $p=0$ and $p=1$.

Scheme for various duct modes is illustrated in Fig. 4,5. Because of symmetry, pairs of natural modes that have the same natural frequency occur. For forced response predictions, it is important to include all pairs to avoid incomplete solutions. Natura frequencies of the assembled structure are slightly different from those of each substructure. It is possible to say that the existence of the shell structure causes stiffening of the plate structure for low frequencies and vise verse for high frequencies, Tables 1,2.

The obtained results are compared with those of finite element method calculated by package cosmos/m $1.7[6,7]$, Table 2. 


\section{Conclusion}

The proposed method is an efficient method in calculating the structure vibration parameters as natural frequencies and mode shapes. The frequency of the assembled structure is a combination of the individual frequencies of the substructures. The first natural frequency of the structure is close to that of the plate structure but with minor modification, increase, due to the existence of shell structure, and so for all natural frequencies. Using the calculated receptance of the shell and plate elements it is possible to calculate the frequencies and mode shapes of any structure that is formed basically from these elements. It is possible, in the proposed method, to perform a parametric study that may be difficult to perform by the finite element programs.

\section{References}

1. Soedel, W., Vibrations of Shells and Plates, Marcel Dekker Inc. N.Y.,(1981),

2. Azimi, S., Hamilton, J. F. and Soedel, W., The Receptance Method Applied To The Free Vibration of Continuous Rectangular Plates, Journal of Sound and Vibration, Vol. 93, (1983).

3. Azimi, S., Natural Frequencies and Modes of Cylindrical Polynomial Ducts Using Receptance Methods, Journal of Sound and Vibration, Vol. 109,(1986).

4. El-Maddah, M, Application of Frequency Method for Substructure Dynamic Coupling, $2^{\text {nd }}$ International Conference on Production Eng. Design \& Control, Univ. of Alex. Egypt, (1982).

5. Blevins, R., Formulas For Natural Frequency And Mode Shape, Van Nostrand Reinhold Company, N.Y.,(1979).

6. COSMOS Finite Element Package, Structural Research and Analysis Corporation, Santa Monica, California, (1993).

7. Wolf, J., Finite-Element Modeling of Underground Media, John Wiely \& Sons, England, (1999).

Table 1 Plate and shell natural frequencies $[\mathrm{Hz}]$

\begin{tabular}{|c|c|c|c|c|c|}
\cline { 2 - 6 } \multicolumn{1}{c|}{} & Mode 1 & Mode 2 & Mode 3 & Mode4 & Mode 5 \\
\hline plate & 3 & 7.6 & 15.2 & 25.9 & 39.6 \\
\hline shell & 35.3 & 37 & 40.3 & 43.7 & 52.9 \\
\hline
\end{tabular}

Table 2 Natural frequencies of the assembled structure $[\mathrm{Hz}]$

\begin{tabular}{|c|c|c|c|c|c|c|}
\cline { 2 - 7 } \multicolumn{1}{c|}{} & Mode 1 & Mode 2 & Mode 3 & Mode 4 & Mode 5 & Mode 6 \\
\hline Proposed Method & 3.45 & 8.4 & 16.2 & 26.2 & 35.4 & 37.3 \\
\hline FEM & 3.2 & 7.45 & 14.3 & 23.1 & 36.4 & 41.7 \\
\hline
\end{tabular}




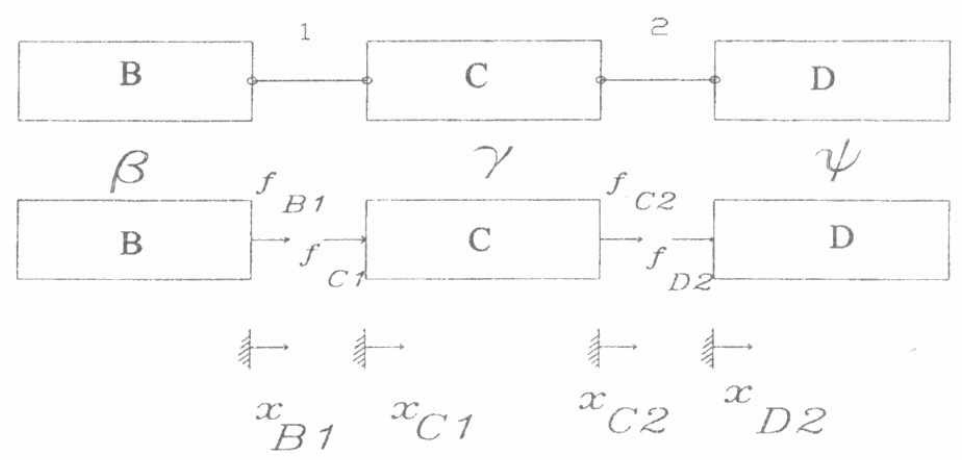

Fig. 1 Problem definition

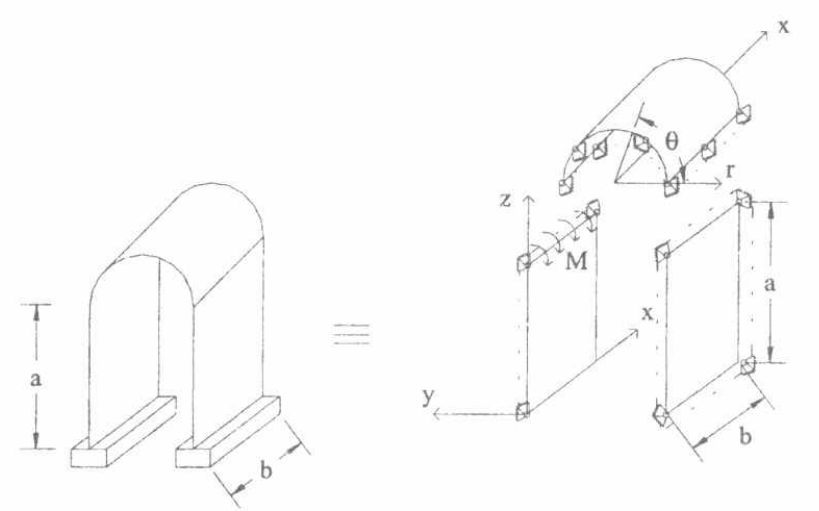

$\begin{array}{ll}\text { a) Assembled structure } & \text { b) Substructure components }\end{array}$

Fig. 2 Proposed structure 

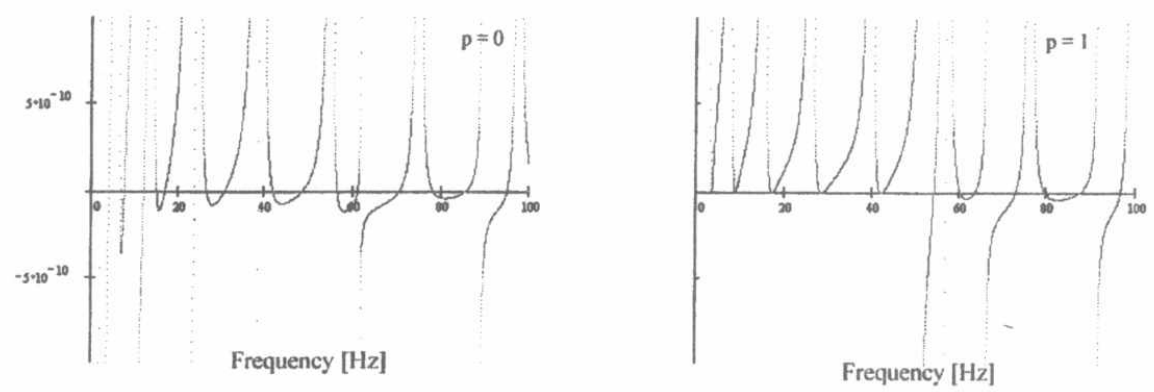

Fig. 3 Solution of the frequency equation
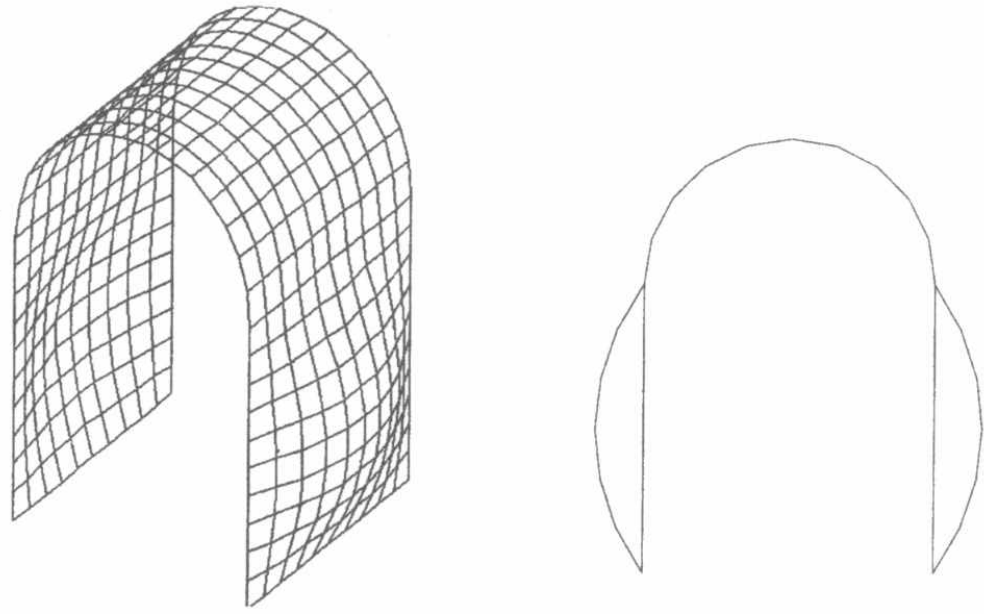

FEM

Receptance

Fig. 4 First mode, $\omega=3.2 \mathrm{~Hz}$ 
D 